\title{
EMPREENDEDORISMO SOCIAL NO ENFRENTAMENTO ECONÔMICO DA COVID-19
}

\section{SOCIAL ENTREPRENEURSHIP IN THE ECONOMIC CONFRONTATION OF COVID-19}

\section{NILVA CELESTINA DO CARMO}

Mestre em Economia Doméstica

Professora do Instituto Federal de Educação Ciência e Tecnologia do Sudeste de Minas Gerais Orcid: https://orcid.org/0000-0002-7520-2382 / E-mail: nilva.carmo@ifsudestemg.edu.br

Av. Dr. José Sebastião da Paixão, s/n, Bairro: Lindo Vale - Rio Pomba - MG, CEP: 36180-000

\section{BRUNA RODRIGUES DE FREITAS}

Mestre em Administração

Professora do Instituto Federal de Educação Ciência e Tecnologia do Sudeste de Minas Gerais Orcid: https://orcid.org/0000-0003-0512-4240 / E-mail: bruna.rodrigues@ifsudetemg.edu.br

\section{CARLA PATRÍCIA GARCIA}

Mestre em Educação

Professora do Instituto Federal de Educação Ciência e Tecnologia do Sudeste de Minas Gerais Orcid: https://orcid.org/0000-0002-0436-3103 / E-mail: carla.garcia@ifsudestemg.edu.br

\section{ANDRÉIA APARECIDA ALBINO}

Doutora em Administração

Professora do Instituto Federal de Educação Ciência e Tecnologia do Sudeste de Minas Gerais Orcid: https://orcid.org/0000-0002-1947-6928 / E-mail: andreia.albino@ifsudestemg.edu.br

\section{BRUNO SILVA OLHER}

Doutor em Economia Doméstica

Professor do Instituto Federal de Educação Ciência e Tecnologia do Sudeste de Minas Gerais Orcid: https://orcid.org/0000-0002-3707-3065 / E-mail: bruno.olher@ifsudestemg.edu.br

\section{Submissão: 29/06/2020. Revisão: 05/11/2020. Aceite: 26/11/2020. Publicação: 29/12/2020.} DOI: http://dx.doi.org/10.22277/rgo.v14i1.5611

\section{RESUMO}

Este artigo visa descrever as características do projeto Rio Pomba e Região de Mãos Dadas, demonstrando não só sua operacionalização como apresentando os resultados conquistados até $\mathrm{o}$ momento. $\mathrm{O}$ relato apresentado assume uma abordagem predominantemente qualitativa, sendo compreendido como um estudo de caso. A maior parte das evidências coletadas tem origem em sua própria experiência. Além disso, fornecedores, consumidores, professores e estudantes envolvidos com a atividade extensionista foram abordados em uma pesquisa de opinião que, inicialmente, teve a finalidade de gerar subsídios para as melhorias do projeto e que, posteriormente, se constituiu em fonte de dados a serem explorados neste relato. Além da apresentação do projeto propriamente dito, foi elaborada uma Análise de Conteúdo. Os resultados colaboram com a disseminação de ideias práticas, que se aproveitam de tecnologias existentes e acessíveis, para impulsionar a economia nesse momento delicado, sem deixar, contudo, de contribuir com aspectos relacionados às boas práticas de manipulação de produtos, tema tão essencial, especialmente na contemporaneidade.

Palavras-chave: COVID 19. Projeto de extensão. Geração de renda. Equilíbrio econômico. Empresas Juniores. 


\begin{abstract}
The expansion of the COVID-19 pandemic has significantly affected global economic activity and, in this context, trade ranks among one of the most affected sectors, given that, in order to contain the spread of the virus, by social isolation, the the closure of many establishments and the prohibition of commercial activities such as open markets. Given the above, some members of the Academic Department of Management Sciences of the Instituto Federal de Educação, Ciências e Tecnologia do Sudeste de Minas Gerais campus - Rio Pomba, in partnership with the companies Juniores Emcomp and Know How, created the project "Rio Pomba e Região de Mãos Dadas", which is ongoing and has produced inspiring results. This project seeks to position itself as one of the alternatives for reducing the economic impacts of COVID-19 in Rio Pomba and the region and, for this purpose, it developed an interactive and easy-to-use material that has brought the end consumer closer to rural producers, small producers merchants and service providers, thus promoting marketing activities and, consequently, generating income. This article aims to describe the characteristics of the project in question, demonstrating not only its operation but also presenting the results achieved so far. Thus, it contributes to the dissemination of practical ideas, which take advantage of existing and accessible technologies, to boost the economy in this delicate moment, without, however, contributing to aspects related to good product handling practices, such an essential topic, especially in contemporary times.
\end{abstract}

Keywords: COVID-19. Extension project. Income generation. Economic balance. Junior Companies.

\title{
1 INTRODUÇÃO
}

No momento de crise provocada pela pandemia do COVID-19, são muitas e de diversas nuances as dificuldades enfrentadas pelos produtores, comerciantes e prestadores de serviços. Isto porque iniciando-se pela esfera federal, e na sequência, estadual, foi reconhecido o estado de calamidade pública no país. O estado de Minas Gerais publicou o Decreto no 47.891 no dia 20 de março de 2020, e a partir daí, medidas específicas na esfera pública passaram a ser tomadas em prol da causa (ALMG, 2020).

No entanto, o Comitê Extraordinário COVID-19, criado pelo Decreto 47.886 de 15 de março de 2020, já havia publicado em 19 de março de 2020, a Deliberação no 8, dispondo nesta as medidas de contenção do novo vírus, que provocaram a interrupção das atividades normais das pessoas, o que impactou negativamente na produção, no consumo corrente e nos investimentos (ALMG, 2020). A gravidade dos efeitos econômicos da COVID-19 deve-se, portanto, à sua capacidade de gerar, ao mesmo tempo, choques negativos na oferta e na demanda agregada mundial (UFRJ, 2020). Os ordenamentos legais trataram da suspensão de atividades relacionadas à educação, comércio, transporte e outras, sendo a orientação pela manutenção do funcionamento somente daquelas consideradas essenciais. Neste caso, feiras, lojas, shopping centers, academias, entre outros estão entre as organizações mais impactadas, uma vez que foram as primeiras a ter as portas fechadas (ALMG, 2020).

Segundo informações da Agência Brasil (2020), o comércio mundial será afetado pela quebra da oferta, por causa da interrupção de fornecimento em diferentes cadeias produtivas e, também, pela queda da demanda em virtude da perda de renda e do aumento do desemprego. 
Nilva Celestina do Carmo, Bruna Rodrigues de Freitas, Carla Patrícia Garcia, Andréia Aparecida Albino e Bruno Silva Olher

Nesse sentido, produtores que comercializavam seus produtos em feiras livres e demais veículos, foram impedidos de continuar com suas atividades, o que gera dificuldade de escoamento da produção, perda de estoques e, principalmente, da capacidade de obtenção de renda. Outros profissionais autônomos, pessoas jurídicas, empregadas domésticas, freelancers, etc. tiveram que deixar de trabalhar e, consequentemente, deixaram de receber também.

De acordo com Serviço Brasileiro de Apoio às Micro e Pequenas Empresas - SEBRAE (2020), o segmento varejo tradicional, seguido por moda, alimentação fora do lar, construção civil, beleza, logística e transporte são os segmentos que mais concentram pequenos negócios e são os que terão as atividades mais afetadas. Os segmentos mais impactados somam 12,3 milhões de empresas, que empregam 21,5 milhões de trabalhadores.

Segundo as informações contidas no Boletim de Impactos COVID-19 nos pequenos negócios, devido as medidas restritivas de comportamento, nas primeiras semanas de março, especificamente no segmento varejo tradicional, houve queda de faturamento de $64 \%$, e esta tende a aumentar. Sendo assim, há a necessidade de implementação de ações que visem minimizar esse impacto.

Adaptar o negócio para entrega direta ou utilizando serviço delivery é uma alternativa interessante para o varejo. Mesmo que o empresário tenha que fechar sua loja física, deve manter contato com os clientes pelos canais digitais e oferecer serviços e manter a comunicação para manter a lembrança do cliente (SEBRAE, 2020, p. 3).

Percebe-se que esta conjuntura tem sido vivenciada em todo o mundo e, no caso do município de Rio Pomba-MG, localizado na Zona da Mata do estado, a situação não é diferente e tem gerado preocupações principalmente àqueles que não possuem renda fixa.

De acordo com os dados do Instituto Brasileiro de Geografia e Estatística (IBGE), o município de Rio Pomba possui aproximadamente 17.000 habitantes, tem 20,8\% de pessoas ocupadas e $33 \%$ da população tem rendimento nominal mensal per capita de até $1 / 2$ salário mínimo (IBGE, 2017).

Os municípios do entorno de Rio Pomba, segundo dados do Censo Demográfico de 2010, também apresentam características semelhantes, sendo que alguns enfrentam situações até mais alarmantes, como Silveirânia e Mercês, que apresentam um percentual de quase $40 \%$ da população com rendimento nominal mensal per capita de até $1 / 2$ salário mínimo e, diante disso, o Departamento Acadêmico de Ciências Gerenciais (DACG) do Instituto Federal de Educação, Ciência e Tecnologia do Sudeste de Minas Gerais - Campus Rio Pomba, em parceria com as empresas Juniores Emcomp e Know How Consultoria Jr., provenientes respectivamente dos cursos de Ciência da Computação e Bacharelado em Administração do mesmo Campus, criou o projeto "Rio Pomba e Região de Mãos Dadas", que visa aproximar consumidores, produtores, comerciantes e prestadores de serviços de modo prático e em conformidade com as normas de higiene e segurança alimentar.

Destaca-se que a participação de empresas juniores no projeto, possibilita aos estudantes nelas inseridos, a oportunidade de ampliar suas experiências acadêmicas e empodera os futuros profissionais com conteúdos relacionados à formação cidadã e política, sendo assim, são "aliadas da formação profissional e buscam unir estudantes matriculados em cursos de graduação, a fim de capacitá-los para o mercado de trabalho, estimular o senso de responsabilidade e desenvolver habilidades" (BRASIL JÚNIOR, 2020).

Diante do exposto, e tendo em vista que o referido projeto tem obtido destaque perante outras instituições de ensino, que pretendem até mesmo replicar a ideia, dos 
produtores cadastrados, dos consumidores e que tem ainda gerado mídia espontânea, especialmente pela rapidez e pela forma prática como tem reagido à situação econômica e social atual, este artigo almeja descrever as características do projeto em questão, demonstrando o seu percurso, desde a elaboração da ideia, passando por sua operacionalização e apresentando os resultados conquistados até o momento.

Este artigo está dividido em quatro seções. No referencial teórico, são abordados os temas: extensão universitária e desenvolvimento profissional, vulnerabilidade econômica e empreendedorismo social, sendo que este último tema emerge como uma das alternativas para mitigar problemas decorrentes das dificuldades econômicas vivenciadas na atualidade. Na sequência, discute-se brevemente a abordagem metodológica empregada, seguida da apresentação do projeto, da concepção aos resultados parciais. Por fim, são elaboradas algumas considerações finais, explorando possibilidades de desdobramentos e implicações futuras.

\section{FUNDAMENTAÇÃO TEÓRICA}

\subsection{AS AÇÕES EXTENSIONISTAS NO DESENVOLVIMENTO PROFISSIONAL}

A formação acadêmica se compõe nas instituições de ensino superior (IES) em geral, sobre uma base tríplice formada por ensino, pesquisa e extensão, tratada na Lei 9394/96, Lei de Diretrizes e Bases da Educação Nacional (LDB), no capítulo que discorre sobre a educação superior. A referida Lei traz, em seu artigo 43, incisos III e VII, o papel deste nível de formação em relação à pesquisa e extensão, respectivamente. Dentre as instituições de ensino superior no Brasil, destaca-se como cenário deste artigo, o Instituto Federal de Educação Ciência e Tecnologia do Sudeste de Minas Gerais (IF Sudeste MG), uma das IES criadas pela Lei 11.892/08, com características que fazem desta uma instituição peculiar em seu papel, e que também se consolida por este tripé, apontando-o como objetivo especificamente em seu artigo 7으 (BRASIL, 2008).

A Lei 11.892/08 traz como papel dos Institutos Federais (IFs) dentre outros, a verticalização do ensino, que possibilita um percurso educacional do ensino médio integrado à formação técnica, até o doutorado (BRASIL, 2008), o que dá singularidade a este modelo institucional. Destaca-se que o tripé da formação acadêmica neste modelo deve fazer parte de toda esta trajetória educacional. Em especial, trata este artigo do componente extensão, junto a alunos da graduação.

A extensão, para Santos, Rocha e Passaglio (2016), permite ir além das salas de aula, conduzindo a um conhecimento teórico-prático que amplia o desenvolvimento dos saberes e a visão crítica que questiona a própria prática profissional. Nesta perspectiva, reforça o papel formador em linhas globais, somado ao empenho dialógico junto à sociedade em seu cotidiano, podendo abranger toda sorte de problemas em áreas distintas. Ainda segundo a Resolução MEC 07/2018, a extensão é reconhecida pelo caráter interdisciplinar, de aplicação prática do conhecimento, tratando ainda que esta prática se dá pelo diálogo com a sociedade em suas questões contemporâneas (BRASIL, 2018).

Surpreendidos por uma pandemia que modificou o cenário mundial, o movimento das IES foi imediato no sentido de responder de forma colaborativa a urgente demanda de ações em várias frentes, essencialmente saúde e economia, por meio da pesquisa e da extensão, conciliando os saberes desenvolvidos nestes espaços e que possam figurar como parte da solução e da possível convivência com o problema que se apresenta. Surge na proposta desenvolvida pela equipe de docentes e discentes do IF Sudeste MG, mediante a 
Nilva Celestina do Carmo, Bruna Rodrigues de Freitas, Carla Patrícia Garcia, Andréia Aparecida Albino e Bruno Silva Olher

contextualização do cenário econômico que se apresenta, a articulação para a prática por meio da extensão, visando desenvolver o empreendedorismo social como coadjuvante neste processo.

\subsection{VULNERABILIDADE ECONÔMICA}

Para discutir a vulnerabilidade econômica é indispensável uma análise da pobreza. Pitombeira (2019) afirma que o conceito de pobreza corresponde ao quanto é preciso para um indivíduo viver em sociedade com as necessidades básicas de alimentação, vestimenta, abrigo, saúde e educação. Assim, quando um cidadão não atinge esse mínimo necessário, estaria enquadrado na linha da pobreza e neste sentido, o cenário atual sobressalta.

Quanto maior for o tempo necessário para conter a pandemia, maiores serão os impactos percebidos pela população e maiores as sequelas na desaceleração econômica, que já atinge o mundo todo, com maior reflexo em sociedades mais vulneráveis, seja em função da elevação das redes de contágio, seja em função dos encadeamentos de consumo e produção impactados em praticamente todos os setores (SENHORAS, 2020).

Para Rogoff (2020), é precoce antecipar os efeitos a longo prazo que a pandemia trará. O autor ressalta que muitas localidades enfrentarão grandes problemas econômicos na próxima década, atrelados ao endividamento e a um choque de oferta e demanda impulsionado pela COVID-19. Gopinath (2020) afirma que tanto a perda de renda quanto o medo de contágio e o aumento da incerteza fazem com que as pessoas gastem menos, o que pode fazer com que as empresas calculem uma demanda menor, reduzam sua produção e as despesas de investimento, acentuando o fechamento de negócios e a perda de empregos. Tal situação deixará um grande contingente de pessoas em situação vulnerável.

Já se percebe que a crise de saúde e econômica imposta pela COVID-19 está elevando o nível de desemprego e precarizando as relações trabalhistas. Dados do IBGE (2020) revelaram que a taxa de desemprego alcançou $14,4 \%$ no trimestre terminado em agosto, demonstrando um aumento de $1,6 \%$ frente ao trimestre encerrado em maio, que foi de $12,9 \%$, ou seja, o número de desempregados atingiu 13,8 milhões, aumento de $8,5 \%$ frente ao trimestre anterior.

O Brasil enfrenta uma condição muito delicada em relação à flexibilidade no mercado de trabalho, relacionada à informalidade econômica, que proporciona ainda menor segurança para o trabalhador. Países em desenvolvimento, especialmente os latino-americanos, têm um setor informal hipertrofiado, portanto, a falta de segurança dos trabalhadores advém, inclusive, de uma característica já existente (KALLEBERG, 2009).

Sob a tutela do Estado, o desempregado se tornou alvo de ações motivadoras das práticas empreendedoras e/ou do trabalho por conta própria. Outras formas de trabalho, além emprego formal, são utilizadas no Brasil como meios de resposta ao desemprego no país. Este fato se evidencia em diversos tipos de ocupações, que corroboram a precariedade do trabalho diante as necessidades de um mercado cada vez mais flexibilizado e do trabalho atípico (BEZERRA, 2019).

\subsection{EMPREENDEDORISMO SOCIAL COMO UMA ALTERNATIVA PARA LIDAR COM A VULNERABILIDADE}

O empreendedorismo é um motor de desenvolvimento de muitos países que hoje estão em destaque na economia mundial, movimentando o cenário econômico, por meio da geração de emprego e da criação de recursos e mercados (CARDOSO, 2015). Em 2018, o Brasil,

RGO - Revista Gestão Organizacional, Chapecó, v. 14, n. 1, p. 316-332, jan./abr. 2021. 
segundo o Global Entrepreneurship Monitor (GEM) apresentou uma TTE (taxa de empreendedorismo total) de $38 \%$, revelando que em cada cinco brasileiros adultos, dois eram empreendedores, correspondendo a estimativa de que 52 milhões de brasileiros entre 18 e 64 anos estavam realizando alguma atividade empreendedora, o que reforça a importância do empreendedorismo para o desenvolvimento socioeconômico.

Para Dornelas (2015), o empreendedorismo está relacionado ao processo de transformação de ideias em oportunidades, no qual o sucesso dependerá da implementação correta das oportunidades. Em linhas gerais, empreender é encontrar uma oportunidade e criar um negócio para capitalizar sobre ela, assumindo riscos calculados. Há também ações empreendedoras que não necessariamente geram um novo negócio.

Contudo, o empreendedorismo sempre está em contínua evolução, adaptando-se ao mercado e com isso uma nova tendência começou a ganhar espaço, o empreendedorismo social. O tema tem como propósito buscar soluções para resolver ou amenizar problemas sociais, econômicos e ambientais e, diante disso, começam a surgir novas organizações, com o intuito de impactar de forma positiva a sociedade (TENÓRIO, 2006). Neste sentido, o empreendedorismo social, um modelo de negócio de cunho social, preza por atender as lacunas que instituições e os programas do Estado não conseguem atingir em sua totalidade (QUELHO, et al., 2014).

Para os autores supracitados, a prática se diferencia do empreendedorismo privado, uma vez que este apesar de ter o objetivo de suprir necessidades humanas, tem o foco no mercado e no lucro, enquanto o empreendedorismo social tem uma missão de oferecer melhores condições para a sociedade. Melo e Froes (2002) enfatizam que enquanto a medida de desempenho do empreendedorismo empresarial é o lucro, a do empreendedorismo social é o impacto social.

O empreendedorismo social engloba organizações que têm uma missão social estabelecida e para isso fazem uso de mecanismos comerciais com os quais procuram a manutenção ou melhoria das condições de vida, de modo que ultrapassem os benefícios financeiros. Dentre elas pode-se citar organizações de filantropia, terceiro setor, trabalhos voluntários e os negócios sociais (VASCONCELOS; LEZANA, 2012).

Melo (2002) reafirma essa finalidade ao dizer que este tipo de empreendedorismo envolve membros da comunidade em um esforço comum de integração e desenvolvimento, produzindo bens e serviços para a comunidade, para que esta tenha condições mais dignas de vida.

Empreender para resolver um problema social ou ambiental tem motivado o surgimento de muitas empresas no Brasil. De acordo com o Centro Integrado de Estudos e Programas de Desenvolvimento Sustentável - CIEDS (2018), uma parceria do Sebrae com o Programa das Nações Unidas para o Desenvolvimento (PNUD) identificou mais de 800 negócios que estão transformando a realidade de pessoas e comunidades por todo o Brasil e, desses negócios, segundo levantamento da Pipe Social, uma vitrine que busca evidenciar iniciativas e negócios de impacto socioambiental no país, em 2019, 63\% estão no Sudeste do país, o que revela um engajamento da região com causas sociais.

Para Dess (2001), existem algumas peculiaridades que caracterizam o empreendedorismo social, quais sejam: missão para criar e manter valor social (não apenas valor privado); busca incansável por novas oportunidades para servir essa missão; envolvimento em um processo de contínua inovação, adaptação e aprendizado e ação com ousadia sem ser limitado por recursos atualmente disponíveis. Baseado nessas características, Santana e Souza (2015) afirmam que o empreendedorismo social está fundamentado na 
Nilva Celestina do Carmo, Bruna Rodrigues de Freitas, Carla Patrícia Garcia, Andréia Aparecida Albino e Bruno Silva Olher

criação de valor social por meio da implementação de inovações de metodologias, produtos ou serviços que gerem transformação social.

Em linhas gerais, os fundamentos do empreendedorismo social visam mitigar problemas como pobreza, fome, não acesso à educação e falta de oportunidades igualitárias, visando à inclusão social. Os produtos e serviços oferecidos atendem às necessidades dos mais pobres, desenvolvendo a cidadania, a igualdade de direitos e oportunidades e a redução das diferenças econômicas e de renda entre as classes econômicas e sociais (CARDOSO, 2015). Empreendedores sociais, portanto, iniciam mudanças a partir da identificação de um problema na sociedade.

\section{DELINEAMENTO METODOLÓGICO}

O relato apresentado neste artigo assume uma abordagem predominantemente qualitativa. Viera (2006, p. 18) explica que "uma importante característica da pesquisa qualitativa é que ela oferece descrições ricas e bem fundamentadas, além de explicações sobre processos em contextos locais identificáveis", algo que se procura fazer neste trabalho, a fim de que o projeto "Rio Pomba e Região de Mãos Dadas" seja bem compreendido e, talvez, até mesmo replicado por outras instituições.

Para tanto, o projeto é compreendido como um estudo de caso que, de acordo com Yin $(2015$, p. 4), "permite que os investigadores foquem um 'caso' e retenham uma perspectiva holística e de mundo real". Uma vez que o projeto Mãos Dadas atua, em alguma medida, interferindo em uma realidade contemporânea e permeada de fatores que trazem oportunidades e ameaças à economia e a outros fatores de caráter social da microrregião em que atua, explicá-lo por meio de um estudo de caso se mostra apropriado. Particularmente adequado para responder questões do tipo "como" e "por que", esta abordagem ofereceu suporte para que se explique o projeto supracitado de modo abrangente, como prevê a classificação do estudo de caso único e de caráter holístico (Yin, 2015).

Considerando que os autores deste artigo trabalharam no projeto "Rio Pomba e Região de Mãos Dadas", a maior parte das evidências coletadas tem origem em sua própria experiência. Além disso, fornecedores, consumidores, professores e estudantes envolvidos com a atividade extensionista foram abordados em uma pesquisa de opinião que, inicialmente, teve a finalidade de gerar subsídios para as melhorias do projeto e que, posteriormente, se constituiu em fonte de dados a serem explorados neste relato. Os comentários e mensagens diretas nas redes sociais do projeto (Fanpage e Instagram) também forneceram subsídios para este artigo.

Além da apresentação do projeto propriamente dito, foi elaborada uma Análise de Conteúdo - AC com os materiais mencionados anteriormente. A AC, segundo Franco (2012, p. $30)$, se inicia "com base no conteúdo manifesto e explícito". No caso do presente trabalho, a unidade de análise utilizada é o tema, que consiste em uma asserção sobre um assunto e que, ainda de acordo com a autora supracitada, é considerado como a mais útil unidade de registro. Uma vez que as avaliações e demais dados disponíveis sobre o projeto "Rio Pomba e Região de Mãos Dadas" não foram, inicialmente, levantados com a finalidade de elaboração de um relato, a categorização foi realizada a posteriori, tendo emergido, portanto, dos dados. 


\section{APRESENTAÇÃO DO PROJETO “RIO POMBA E REGIÃO DE MÃOS DADAS”}

\subsection{A IDEIA}

No Departamento Acadêmico de Agroecologia do IF Sudeste MG - Campus Rio Pomba existe o projeto Mãos à Horta, que interliga produtores agroecológicos a consumidores, disponibilizando por e-mail uma planilha com os itens que estão à venda e que são entregues aos consumidores na feira livre da cidade (BARBOSA et al., 2017). Frente ao cenário da pandemia, procurou-se, por meio do projeto "Rio Pomba e Região de Mãos Dadas", trabalhar de forma semelhante ao Mãos à Horta, porém ampliando a ideia, atingindo não somente os feirantes. $\mathrm{O}$ objetivo era criar uma plataforma virtual de fácil acesso tanto para consumidores quanto para fornecedores. Assim, a primeira reunião para tratar do assunto foi realizada no dia 19 de março de 2020, poucos dias depois do início do isolamento social em Rio Pomba.

Diante disso, conforme será explicado no tópico subsequente, foi estruturada a equipe e a divulgação do projeto começou a atingir, inicialmente, os municípios de Rio Pomba, Mercês, Piraúba, Tocantins, Barbacena, Rio Novo, Dores do Turvo e Ubá. Cerca de outros 30 municípios da região também serão incluídos no site do projeto, que está em fase final de desenvolvimento.

Após a primeira reunião com a equipe, optou-se por criar, além do site, um arquivo denominado "PDF Interativo", que permite contato direto com os fornecedores e que é utilizado como catálogo de produtos e tem sido divulgado por meio de diversas mídias e redes sociais, periodicamente. $O$ adensamento da proposta em seu delineamento inicial e objetivos é análogo à geração de valor social, base em que, segundo Santana e Souza (2015), fundamenta-se o empreendedorismo social, passando a ser esta mais uma característica do projeto.

\subsection{BUSCA POR PARCEIROS E DEFINIÇÃO DAS ATRIBUIÇÕES}

Para iniciar as atividades, foi necessário compor uma equipe com competências e habilidades diversas. No primeiro momento, procurou-se por pessoas do DACG que quisessem contribuir e, então, realizou-se uma análise do perfil profissional de cada voluntário, a fim de que, na composição do grupo de trabalho, todas as competências e habilidades necessárias fossem contempladas.

O próximo passo envolveu o convite aos integrantes das empresas juniores Know How Consultoria Jr. e da Emcomp. A ideia foi bem recebida por ambas e dois professores do Departamento Acadêmico de Ciência da Computação - DACC também passaram a integrar o projeto.

No total, o projeto conta com a participação de 33 pessoas (10 docentes, 1 técnica administrativa, 21 discentes e um bolsista). As atribuições foram definidas conforme mostra a Figura 01. Para o gerenciamento do projeto tem-se uma coordenação geral e duas coordenações adjuntas, sendo uma de tecnologia e outra de assessoria, que traçam os objetivos estratégicos e oferecem suporte a todas as atividades.

A coordenação de tecnologia se responsabiliza pela produção do site, dos arquivos de PDF interativos, do aplicativo do projeto e da elaboração das artes que comporão o site, o PDF e as redes sociais. A coordenação de assessoria, por sua vez, é responsável por todas as ações pertinentes à área de gestão do projeto, compreendendo o setor de divulgação, o de elaboração de ações voltadas à disseminação de boas práticas de higiene, bem como a área de relações institucionais. 
Nilva Celestina do Carmo, Bruna Rodrigues de Freitas, Carla Patrícia Garcia,

Andréia Aparecida Albino e Bruno Silva Olher

Figura 1 - Fluxograma do projeto

\begin{tabular}{|c|c|c|c|}
\hline $\begin{array}{c}\text { Captação de } \\
\text { fornecedores }\end{array}$ & $\begin{array}{c}\text { Obtenção de } \\
\text { imagens e descrições }\end{array}$ & $\begin{array}{c}\text { Cadastro dos } \\
\text { fornecedores }\end{array}$ & $\begin{array}{c}\text { Pesquisa de satisfação } \\
\text { e coleta de feedbacks }\end{array}$ \\
$\begin{array}{c}\text { Após todo material ser } \\
\text { recolhido, são cadastrados } \\
\text { efetivamente em suas } \\
\text { categorias de produtos e } \\
\text { município de atuação. }\end{array}$ & $\begin{array}{c}\text { Posteriormente é feito o } \\
\text { primeiro contato direto com } \\
\text { a finalidade de obter fotos } \\
\text { dos produtos, logomarcas e } \\
\text { descrições relevantes que } \\
\text { melhor os identifica. }\end{array}$ & $\begin{array}{c}\text { Nesta primeira etapa, os } \\
\text { fornecedores interessados } \\
\text { respondem um formulário } \\
\text { que contém algumas } \\
\text { informações iniciais para o } \\
\text { cadastramento deles na } \\
\text { plataforma digital e no PDF. }\end{array}$ & $\begin{array}{c}\text { período pré-estabelecido, é feito } \\
\text { contato novamente } \\
\text { com os fornecedores a fim } \\
\text { de pesquisar a satisfação } \\
\text { dele com o projeto. }\end{array}$ \\
$\begin{array}{c}\text { Também se obtém, nesta etapa, } \\
\text { sugestões de melhorias, que } \\
\text { sempre são avaliadas e, se } \\
\text { pertinentes, implementadas. }\end{array}$ \\
\hline
\end{tabular}

Fonte: elaborada pelos autores (2020).

Todas essas áreas são apoiadas pelos integrantes das empresas juniores, que possuem espaço para contribuir não só com as atividades operacionais, mas também para participar das decisões mais estratégicas, o que faculta a esses discentes o aprendizado mais aprofundado. Este modo de trabalho vai ao encontro do que preconizam Santos, Rocha e Passaglio (2016), que defendem, conforme já evidenciado neste artigo, o desenvolvimento de saberes e de uma visão crítica capaz de questionar as próprias decisões e ações.

\subsection{BUSCA POR PRODUTORES PARA CADASTRO}

A busca por fornecedores para integrarem o projeto foi realizada por diferentes meios, quais sejam: i) disponibilização de um formulário do Google para que cada interessado inserisse seu nome, o modo como é conhecido na cidade, a lista de produtos ou serviços que comercializa e seu contato telefônico; ii) ampla divulgação do formulário nas redes sociais do DACG, nos grupos de aplicativo de bate-papo dos docentes, no e-mail institucional e no site do Campus Rio Pomba; iii) entrevista do coordenador do projeto na principal rádio da cidade, que expande seu raio de atuação para a microrregião; iv) contato dos integrantes da equipe com vereadores e demais trabalhadores vinculados às prefeituras, com entidades como a Empresa de Assistência Técnica e Extensão Rural (EMATER), Sindicatos de Trabalhadores e outras, a fim de obter apoio na divulgação; v) divulgação boca em boca por parte dos próprios integrantes da equipe; vi) criação de contas em redes sociais exclusivas para o projeto.

\subsection{DESENVOLVIMENTO DA FERRAMENTA}

Desde o início do projeto, pretendeu-se criar um site que permitisse ao fornecedor fazer seu auto cadastro, estando este sujeito apenas à aprovação de algum integrante da equipe. A aprovação visava evitar a publicação de conteúdos de caráter ilícito, bem como verificar a adequação de vocabulário e a qualidade das imagens dos produtos.

Entretanto, considerando que o desenvolvimento do site demoraria cerca de 30 dias e que a situação vivenciada pelo país e pela região demandava respostas mais rápidas, optouse por elaborar, inicialmente, um arquivo em formato PDF interativo, que permitia que, quando o consumidor encontrasse algum fornecedor e produtos de seu interesse, clicasse no link do aplicativo de bate-papo e fosse direcionado para uma conversa privada com aquele fornecedor e permitia, ainda, que ao clicar no link "telefone", fosse realizada uma chamada para o fornecedor. Com o arquivo PDF disponível, optou-se por mantê-lo como catálogo mesmo depois de o site estar disponível para utilização. 
A primeira versão do arquivo PDF foi disponibilizada ao público 11 dias após o início do projeto e o site, 9 dias depois do PDF com o link: http://projetomaosdadas.emcomp.com.br/. Um recorte da página principal do site é apresentado na Figura 2.

Figura 2 - Página principal do site do projeto

Projeto Masos Dadas

Inicio Sobre Cadastrar no sistema Contato

\section{Escolha sua cidade}
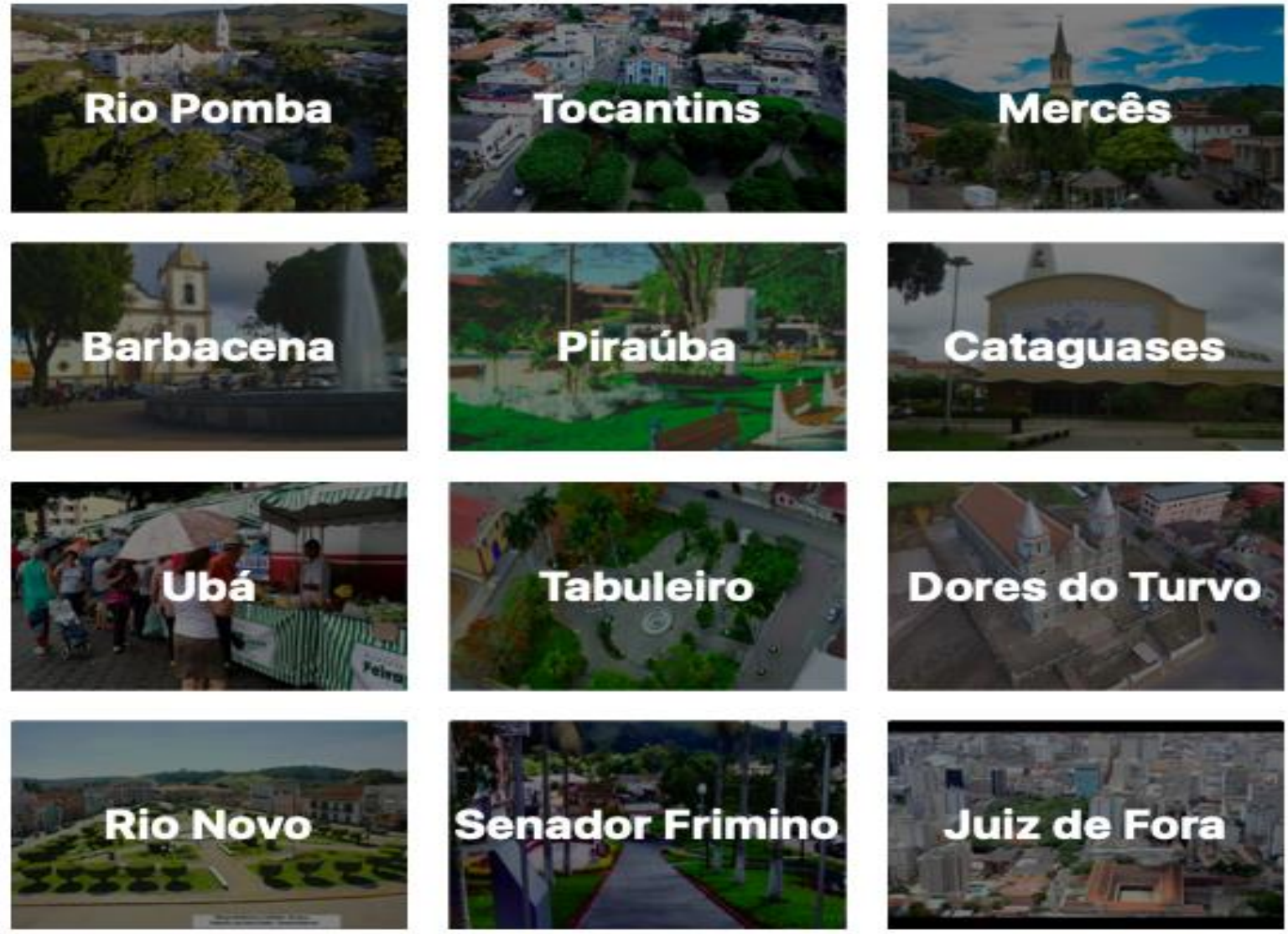

Fonte: página inicial do site do projeto (2020).

Em todas as etapas do projeto, prezou-se pela clareza e simplicidade das informações transmitidas aos consumidores e fornecedores. Procurou-se desenvolver ferramentas que facilitassem o máximo seu uso, a fim de que estas tornassem a experiência do usuário simples e agradável. Adolpho (2011, p. 132), ao defender a simplicidade de utilização e eficiência dos canais digitais, mais especificamente a de um site, afirma que este "não pode ser um jogo de adivinhações com o usuário".

Um aplicativo encontra-se em fase final de elaboração e este tende a tornar ainda mais simples o processo de negociação.

Por fim, tem sido disponibilizada informações claras e simples sobre os cuidados para evitar a contaminação dos produtos e das pessoas envolvidas com o processo de entrega e recebimento, por meio de vídeos didáticos e cartilhas que orientavam sobre a venda e manuseio seguros pelo aspecto sanitário. 
Nilva Celestina do Carmo, Bruna Rodrigues de Freitas, Carla Patrícia Garcia, Andréia Aparecida Albino e Bruno Silva Olher

\subsection{RESULTADOS PARCIAIS}

Até o momento, há 250 fornecedores cadastrados, pertencentes à Rio Pomba e outras 20 cidades do entorno, conforme disposto na Figura 1.

Figura 2 - Municípios atendidos pelo projeto.

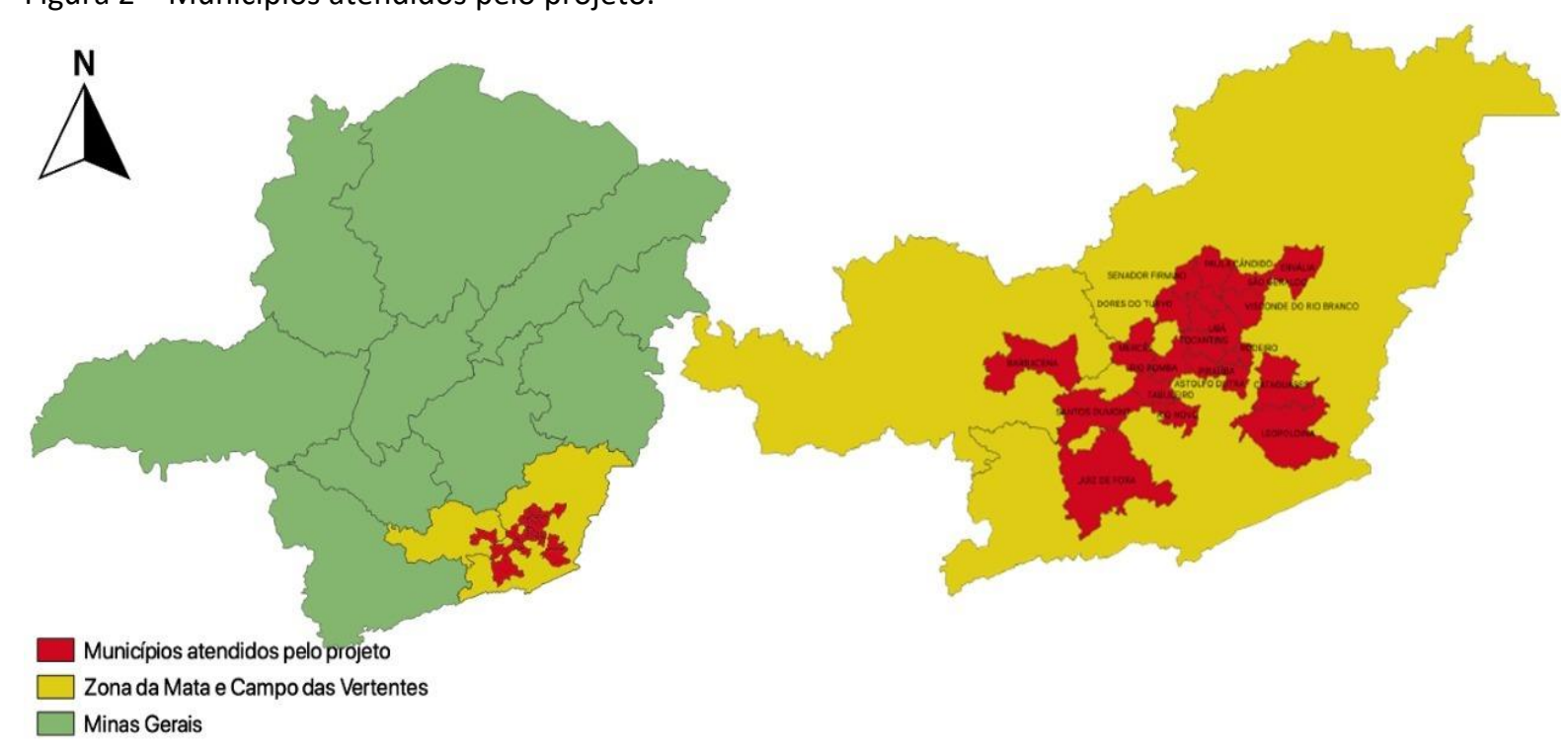

Fonte: elaborada pelos autores (2020).

Dada a rapidez e o nível de organização com que o DACG agiu localmente diante do momento vivenciado pelo mundo, o projeto obteve, desde seu início, forte adesão por parte de fornecedores e consumidores, bem como despertou o interesse de outros campus do IF Sudeste MG. Para além disso, Institutos Federais de outras localidades demonstraram interesse em replicá-lo. Até o momento, os Institutos Federais do Acre, de Minas Gerais, da Bahia e de Goiás e a EMATER-BH se manifestaram com esta intenção.

Pelas avaliações recebidas dos consumidores e dos fornecedores, fica evidente que o projeto está atingindo seu objetivo, que é aproximar os consumidores dos produtores, comerciantes e prestadores de serviços, facilitando o contato entre eles. Os relatos a seguir, que são apresentados sem edição de linguagem, demonstram isso:

\footnotetext{
Já apareceu várias pessoas ligando fazendo pedidos. Obrigado. Obrigado. (Fornecedor de hortifruti)

Está sendo muito válido. Muito obrigada. Parabéns pela iniciativa. (Fornecedora de salgadinhos).

Achei super prático e fácil de usar. Fiz algumas compras e fui bem atendida. Penso que esse projeto ajudará muito os produtores e também os consumidores. (Consumidora).
}

O projeto também tem gerado mídia espontânea. No dia 30/03, o G1 publicou, no link https://g1.globo.com/mg/zona-da-mata/noticia/2020/03/30/projeto-desenvolvido-em-riopomba-liga-comerciantes-e-consumidores-em-cidades-da-zona-da-mata.ghtml, informações sobre ele e isso também serviu como elemento de divulgação. A TV Integração, afiliada da Rede Globo e TV Alterosa, afiliada do SBT, por sua vez, destacaram sua facilidade de uso e sua importância econômica. Além disso, algumas emissoras de rádio da região têm veiculado notícias sobre o trabalho.

Os discentes das empresas juniores também demonstram sua satisfação com a oportunidade de aprendizado e, ao mesmo tempo, de contribuir com melhorias nesse momento ímpar. É o que mostram os relatos a seguir: 
[...] O projeto Mãos Dadas ajuda consolidar todo o conhecimento adquirido durante o curso, e devolver de forma a ajudar toda a região a se manter nesse momento complicado. Ainda há muito a ser feito, e faremos o possível ajudar a todos comerciantes e produtores da região a manterem o seu ganha pão. (Integrante da Emcomp).

O projeto, em primeiro lugar, me traz uma sensação de ser útil em meio a uma crise tão grande. E ser útil, ajudando os pequenos produtores, comerciantes e prestadores de serviços da região, que serão tão afetados, é algo que só adiciona satisfação pessoal. [...] nossos colaboradores estão se empenhando ao máximo para que todo o trabalho possa ser feito da melhor forma possível e possamos ajudar a todos no final, mesmo que com pequenos gestos. Além do sentimento pessoal em participar, o aprendizado profissional é algo que também deve ser citado. Considerando a grande equipe que está por trás de todo os processos, a experiência de organização, de responsabilidade em grupo e de poder participar com professores que compartilham seus conhecimentos fora da sala de aula é algo que me deixa muito feliz. [...]. (Integrante da Know How Consultoria Jr.).

Como é possível perceber, o projeto tem conseguido proporcionar oportunidades de negócios, facilitando acesso a produtos e serviços para os consumidores.

Cardoso $(2015$, p.25) relata que "o empreendedorismo social inicia e lidera mudanças na sociedade. Trabalha para garantir que ideias tomem seu caminho e verdadeiramente mudem o pensamento, a fala e o comportamento das pessoas".

Além disso, o projeto tem promovido aprendizado para os estudantes e até mesmo para os docentes. Tem, ainda, inspirado ações de outras localidades. Para Deslandes e Arantes (2017, p. 180), “o meio está inserido na formação curricular acadêmica, assim como a academia deve estar inserida no meio em que se encontra" e o Mãos Dadas vai ao encontro do que preconiza a extensão universitária, adaptando-se rapidamente a uma situação global e respondendo com agilidade.

O Quadro 01 apresenta os resultados do projeto categorizados quando da realização da AC. Por questões de limitação de espaço neste artigo, optou-se por não se elaborar uma análise mais aprofundada de cada categoria.

Quadro 1 - Categorização dos resultados do projeto.

\begin{tabular}{|c|l|}
\hline $\begin{array}{c}\text { Categoria } \\
\text { profissional } \\
\text { pro com a prática }\end{array}$ & $\begin{array}{l}\text { Apresentação } \\
\text { Os estudantes envolvidos com o projeto salientaram diversas vezes que } \\
\text { foram expostos a situações práticas dos cursos, algo que aprimorou } \\
\text { suas habilidades decisórias e operacionais. }\end{array}$ \\
\hline \multirow{5}{*}{ Trabalho voluntário } & $\begin{array}{l}\text { Alguns estudantes já haviam desenvolvido trabalhos voluntários e } \\
\text { outros não. Para ambos os casos, os estudantes evidenciaram que a } \\
\text { sensação de poder ajudar ao próximo foi algo muito positivo, que Ihes } \\
\text { trouxe mais propósito e satisfação pessoal. }\end{array}$ \\
\hline empresas juniores & $\begin{array}{l}\text { Considerando que o projeto demandava muitas ações por parte das } \\
\text { empresas juniores, estas necessitaram se organizar melhor, convidar } \\
\text { novos membros para integrarem seu quadro de colaboradores. A Know } \\
\text { How Consultoria Jr., inclusive, em parte devido à publicidade que o } \\
\text { Mãos Dadas lhe trouxe, conseguiu se filiar ao Núcleo de Empresas } \\
\text { Juniores da Zona da Mata Mineira (entidade que representa } 58 \\
\text { empresas juniores, que tem como objetivo auxiliar no direcionamento } \\
\text { dos objetivos e no aumento do impacto da cultura empreendedora na } \\
\text { região), o que, por sua vez, Ihe conferiu maior destaque no cenário das } \\
\text { empresas juniores, bem como lhe possibilitou captar mais clientes. }\end{array}$ \\
\hline
\end{tabular}


Nilva Celestina do Carmo, Bruna Rodrigues de Freitas, Carla Patrícia Garcia,

Andréia Aparecida Albino e Bruno Silva Olher

\begin{tabular}{|c|c|}
\hline Multidisciplinaridade & $\begin{array}{l}\text { O projeto permitiu que os estudantes trabalhassem em diversas áreas } \\
\text { de seus respectivos cursos e, além disso, demandou a constante troca } \\
\text { de saberes entre os cursos, de modo que os futuros profissionais da } \\
\text { Ciência da Computação não apenas praticaram os conteúdos de sua } \\
\text { própria área, como tiveram oportunidade de participar das atividades } \\
\text { administrativas. Já os profissionais do curso de Administração, além de } \\
\text { adquirirem um pouco mais de experiência em todas as áreas } \\
\text { administrativas, tiveram contato com rotinas mais próprias da área de } \\
\text { desenvolvimento de tecnologias, o que representa um ganho em sua } \\
\text { formação. Para além disso, a oportunidade que todos tiveram de } \\
\text { trabalhar em equipes multidisciplinares contribuiu com o } \\
\text { desenvolvimento de habilidades de comunicação, liderança e } \\
\text { negociação. }\end{array}$ \\
\hline $\begin{array}{l}\text { Aquecimento da } \\
\text { economia }\end{array}$ & $\begin{array}{l}\text { O projeto interligou comerciantes e consumidores, viabilizando a } \\
\text { manutenção das atividades comerciais, permitindo que os produtos e } \\
\text { serviços ficassem expostos, possibilitando negociações diretas. O } \\
\text { auxílio para que se mantivesse as atividades comerciais contribuiu para } \\
\text { que a economia local não sofresse tantos danos quanto aqueles } \\
\text { esperados em função do isolamento social, minimizando as sequelas da } \\
\text { desaceleração econômica. }\end{array}$ \\
\hline $\begin{array}{l}\text { Reafirmação do papel do } \\
\text { IF perante a população }\end{array}$ & $\begin{array}{l}\text { Destaca-se que houve um estreitamento do relacionamento, tanto na } \\
\text { interação com os arranjos produtivos locais e regionais, quando se } \\
\text { disponibiliza tecnologias (consultoria técnica, site, aplicativo, } \\
\text { divulgação nas redes sociais, etc.) para que os produtores, } \\
\text { comerciantes e prestadores de serviços, de forma rápida e objetiva, } \\
\text { apresentassem e disponibilizassem seus produtos, quanto diretamente } \\
\text { com a população, proporcionando a ela o acesso imediato aos contatos } \\
\text { e, assim, viabilizando a manutenção do isolamento social. Sendo assim, } \\
\text { o IF, como instrumento transformador, cumpriu o seu papel social, ao } \\
\text { promover tanto a produção do conhecimento, quanto a aplicabilidade } \\
\text { deste. }\end{array}$ \\
\hline
\end{tabular}

Fonte: elaborado pelos autores (2020).

Como é possível perceber, o projeto "Rio Pomba e Região de Mãos Dadas" trouxe benefícios e aprendizado para todos os envolvidos.

\subsection{PRÓXIMAS ETAPAS}

Considerando a rápida disseminação do projeto, a busca por informações quanto ao cadastro de fornecedores foi maior do que o esperado e parte do público encontrava dificuldades para inserir seus dados. O esclarecimento dessas dúvidas, bem como o atendimento às várias localidades que se manifestaram com o intuito de replicar o projeto levaram à necessidade de definir mais objetivamente as funções de cada integrante, bem como de recrutar mais pessoas da área de ciência da computação, que poderão contribuir com a implementação de ferramentas que tornem a experiência dos usuários - fornecedores e clientes - mais simples.

O nível de satisfação dos fornecedores e clientes está sendo investigado, a fim de identificar aspectos falhos e adotar as medidas corretivas que se fizerem necessárias.

Embora o projeto tenha sido rapidamente registrado nos editais de fluxo contínuo de extensão do Campus Rio Pomba, as etapas futuras são: proteção da linguagem utilizada no 
site, já em andamento; busca por fontes de financiamento, dentre essas, bolsas que permitam a dedicação exclusiva dos estudantes.

Para após a pandemia, espera-se que os fornecedores cadastrados firmem parcerias com as empresas juniores envolvidas, no sentido de consultorias em suas respectivas áreas, o que poderá ser um benefício a médio e longo prazo agregado ao projeto, tanto para o desenvolvimento de ambas as partes, quanto para o aprendizado individual dos alunos atuantes.

\section{CONSIDERAÇÕES FINAIS}

Espera-se que o compartilhamento das ações do projeto "Rio Pomba e Região de Mãos Dadas", com a comunidade acadêmica, por meio do relato presente neste artigo, contribua com a disseminação de ideias práticas para o enfrentamento da crise econômica.

Além disso, espera-se também inspirar outras empresas juniores quanto ao seu potencial de atuação na sociedade. As ações implementadas oportunizaram aos estudantes a prática dos saberes desenvolvidos ao longo dos cursos e experiências satisfatórias na relação com o mundo do trabalho.

Acrescente-se a isso a possibilidade de alguns fornecedores demandarem, conforme dito, atividades específicas de consultoria e, estreitarem o relacionamento com as empresas juniores. Para alguns comerciantes, o projeto pode representar um primeiro passo no seu processo de transição para o e-commerce. Essas melhorias vislumbradas poderão tornar esses fornecedores mais organizados, preparados para as demandas da atualidade, melhorando a relação com os clientes e a sua lucratividade.

Para o caso de outras instituições pretenderem desenvolver projetos semelhantes ao "Rio Pomba e Região de Mãos Dadas", é possível incorporar outras expertises. Dar voz à multidisciplinaridade para contribuir com o público-alvo desse tipo de atividade em áreas distintas (a exemplo da psicologia, que em momentos como o atual, pode contribuir muito) é algo desejável e com potencial para trazer resultados mais robustos para as ações empreendidas.

Cabe mencionar, por fim, que a iniciativa "Rio Pomba e Região de Mãos Dadas" está em constante aprimoramento, mesmo durante a escrita deste relato. Considerando que todas as suas atividades foram desenvolvidas com rapidez, há espaço e oportunidade para que as ações se aprimorem e que novas estratégias sejam adotadas. Este trabalho se limitou a apresentar o projeto em plena fase de desenvolvimento, de modo que, no futuro, espera-se que o Mãos Dadas esteja mais amadurecido e que contemple melhorias em diversas funções que desenvolve.

Às instituições interessadas em atuar de forma semelhante, espera-se que as ações aqui descritas contribuam para um trabalho na busca por melhorias para a população.

Por fim, é necessário agradecer aos demais professores que contribuíram pontualmente com o projeto e aos discentes, aspecto principal da instituição.

\section{REFERÊNCIAS}

ADOLPHO, C. Os 8 Ps do marketing digital: o guia estratégico de marketing digital. São Paulo: Novatec, 2011.

ASSEMBLÉIA LEGISLATIVA DE MINAS GERAIS - ALMG. DIÁRIO DO EXECUTIVO. Decreto 47.891 de 20 de março de 2020. Reconhece estado de calamidade pública no estado 
Nilva Celestina do Carmo, Bruna Rodrigues de Freitas, Carla Patrícia Garcia, Andréia Aparecida Albino e Bruno Silva Olher

decorrente da pandemia causada pelo agente Coronavírus (COVID-19), 2020. Minas Gerais, 2020. Disponível em:

https://www.saude.mg.gov.br/images/noticias_e_eventos/000_2020/coronaviruslegislacoes/25-03/Decreto-n-47.891-20.03.20.pdf. Acesso em: 12 nov. 2020.

ASSEMBLÉIA LEGISLATIVA DE MINAS GERAIS - ALMG. DIÁRIO DO EXECUTIVO. Deliberação do Comitê Extraordinário COVID-19 no 8 de 19 de março de 2020. Dispõe sobre medidas emergenciais a serem adotadas pelo Estado e municípios enquanto durar a situação de emergência em saúde pública no Estado. Minas Gerais, 2020. Disponível em:

https://www.saude.mg.gov.br/images/noticias_e_eventos/000_2020/coronaviruslegislacoes/Delib_COES_n_08-de-19.03.2020.pdf. Acesso em: 12 nov. 2020.

BARBOSA, F. D.; CAMPOS, V. P. C.; GOUVEIA, L. V. P.; FERREIRA, H. S.; SOARES, I. A.; CARVALHO, C. M. Rede de prossumidores cooperando com a transição agroecológica: uma experiência da rede "Mãos à Horta", em Rio Pomba - MG. In: VI Congresso Latino-americano de Agroecologia; X Congresso Brasileiro de Agroecologia; V Seminário de Agroecologia do Distrito Federal e Entorno; 12 a 15 de setembro de 2017, Brasília/DF. Anais.... Brasília: 2017. Disponível em: http://cadernos.aba-

agroecologia.org.br/index.php/cadernos/article/view/136. Acesso em 12 nov. 2020.

BEZERRA, A. L. O enfrentamento do desemprego sob a legitimação do trabalho precarizado no Brasil do século XX1 In: CONGRESSO BRASILEIRO DE ASSISTENTES SOCIAIS. Brasília: 2019.

BRASIL. 11.892. Lei $\mathbf{1 1 . 8 9 2}$ de 29 de dezembro de 2008. Dispõe sobre a criação dos Institutos Federais de Educação Ciência e Tecnologia. 2008. Disponível em: http://www.planalto.gov.br/ccivil_03/_ato2007-2010/2008/lei/l11892.htm. Acesso em: 12 nov. 2020.

BRASIL. 9.394. Lei $\mathbf{9 . 3 9 4}$ de 20 de dezembro de 1996. Estabelece as diretrizes e bases da educação nacional, 1996. Disponível em:

http://www.planalto.gov.br/ccivil_03/leis/I9394.htm. Acesso em 12 nov. 2020.

BRASIL. Resolução $n^{\circ} 7$ de 18 de dezembro de 2018. Estabelece as diretrizes para a Extensão na Educação Superior Brasileira e outras providências, 2018. Disponível em:

http://portal.mec.gov.br/index.php?option=com_docman\&view=download\&alias=104251rces007-18\&category_slug=dezembro-2018-pdf\&Itemid=30192. Acesso em: 05 abr. 2020.

BRASIL. Cepal: crise por causa de covid-19 será uma das piores do mundo. Disponível em: https://agenciabrasil.ebc.com.br/economia/noticia/2020-03/cepal-crise-por-causa-de-covid19-sera-uma-das-piores-do-mundo. Acesso em: 05 abr. 2020.

BRASIL JÚNIOR. Confederação Brasileira de Empresas Juniores. Disponível em: https://brasiljunior.org.br/ . Acesso em: 10 nov. 2020.

CARDOSO, G. Mude, você, o mundo! São Caetano do Sul: São Paulo, 2015. 
CIEDS. Mapeamento de Negócios Sociais. Disponível em: https://www.cieds.org.br/noticias/detalhe/mapeamento-de-negocios-sociais. Acesso em: 5 abr. 2020.

DEES, J. G. The meaning of "Social Entrepreneurship" Center for Social Innovation, 2001.

DESLANDES, M. S.; ARANTES, A. R. A extensão universitária como meio de transformação social e profissional. Sinapse Múltipla, v. 6, n. 2, p. 179-183, 2017. Disponível em: http://periodicos.pucminas.br/index.php/sinapsemultipla/article/view/16489. Acesso em: 5 abr. 2020.

DORNELAS, J. Empreendedorismo: transformação ideias em negócios. 5. ed. Rio de Janeiro: Empreende/LTC, 2015.

FRANCO, A. M. P. B. Análise de conteúdo. 4. ed. Brasília: Liber Livro, 2012.

GLOBAL ENTREPRENEURSHIP MONITOR (GEM). Empreendedorismo no Brasil: relatório executivo. Curitiba: IBQP, 2018.

GOPINATH, G. Limiting the economic fallout of the coronavirus with large targeted policies. 2020. Disponível em: https://blogs.imf.org/2020/03/09/limiting-the- economic-fallout-ofthe-coronavirus-with-large- targeted-policies. Acesso em: 05 abr. 2020.

HOFFMANN, R. Medidas de pobreza. In: Hoffmann, R. Estatística para Economistas. São Paulo: Cengage Learning, 2011.

IBGE - INSTITUTO BRASILEIRO DE GEOGRAFIA E ESTATÍSTICA, 2017. Disponível em: https://cidades.ibge.gov.br/brasil/mg/rio-pomba/panorama. Acesso em: 5 abr. 2020.

IBGE - INSTITUTO BRASILEIRO DE GEOGRAFIA E ESTATÍ́STICA. Agência IBGE notícias, 2020. Disponível em: https://agenciadenoticias.ibge.gov.br/agencia-noticias/2012-agencia-denoticias/noticias/29321-desemprego-chega-a-14-4-no-trimestre-encerrado-em-agosto. Acesso em: 11 nov.2020.

KALLEBERG, A. Precarious work, insecure workers: Employment relations in transition. American Sociological Review, v. 74, n. 1, p. 1-22, 2009.

DOI: $10.1177 / 000312240907400101$.

PITOMBEIRA, L. D. Uma perspectiva multidimensional para a pobreza no mercado de trabalho brasileiro em 2005 e 2015. 2019. 86 f. Dissertação (Mestrado). Universidade Federal de Minas Gerais, Minas Gerais, 2019.

QUELHO, A. A. CARVALHAL, S. V.; ALMEIDA, L. C. S. ALMEIDA, C. Empreendedorismo social: Legados da formação cidadã para os anos 80 de Londrina. Londrina: Magz, 2014.

RAVALLION, M. Poverty lines in theory and practice The World Bank, 1998. 
Nilva Celestina do Carmo, Bruna Rodrigues de Freitas, Carla Patrícia Garcia, Andréia Aparecida Albino e Bruno Silva Olher

ROGOFF, K. That 1970s feeling. 2020. Disponível em: https://www.projectsyndicate.org/commentary/next-global-recession- hits-the-supply-side-by-kenneth-rogoff2020-03. Acesso em: 5 abr. 2020.

ROWNTREE, B. Poverty: a study of town life. Macmillan, 1901.

SANTANA, A. J.; SOUZA, L. M. Empreendedorismo com foco em negócios sociais. Curitiba: NITS UFPR, 2015.

SANTOS, J. H.; ROCHA, B. F.; PASSAGLIO, K. T. Extensão Universitária e Formação no Ensino Superior. Revista Brasileira de Extensão Universitária, v. 7, n. 1, p. 23-28, 2016. DOI: https://doi.org/10.36661/2358-0399.2016v7i1.3087.

SEBRAE. Impactos e tendências da COVID-19 nos pequenos negócios, 2020. Disponível em: https://bibliotecas.sebrae.com.br/chronus/ARQUIVOS_CHRONUS/bds/bds.nsf/bc82182840a f8e3bc3004f129d85a5b1/\$File/19395.pdf. Acesso em: 5 abr. 2020.

SENHORAS, E. M. Novo Coronavírus e seus impactos econômicos no mundo. Boletim Conjuntura (BOCA), p. 39-42, 2020. DOI: http://dx.doi.org/10.5281/zenodo.3761708.

TENÓRIO, F. G. Gestão de ONGs: principais funções gerenciais. Rio de Janeiro: Fundação Getúlio Vargas, 2006.

UFRJ - UNIVERSIDADE FEDERAL DO RIO DE JANEIRO. Coronavírus: pesquisadores da UFRJ avaliam impacto econômico da doença, 2020. Disponível em:

https://ufrj.br/noticia/2020/03/18/coronavirus-pesquisadores-da-ufrj-avaliam-impactoeconomico-da-doenca. Acesso em: 5 abr. 2020.

VASCONCELOS, A. M.; LEZANA, A. G. Modelo de ciclo de vida de empreendimentos sociais. RAP - Revista de Administração Pública, p. 1037-1058, 2012. DOI:

https://doi.org/10.1590/S0034-76122012000400007.

VIERA, M. M. F. Por uma boa pesquisa (qualitativa) em administração. In: Pesquisa qualitativa em Administração. Org: VIERA, M. M. F.; ZOUAIN, D. M. 2. ed. Rio de Janeiro: FGV Editora, 2006.

YIN, R, K. Estudo de caso: planejamento e métodos. 5. ed. Porto Alegre: Bookman, 2015. 